\title{
Anti-CXCL13 and Anti-TNFa Monoclonal Antibodies Combinatorial Treatment Inhibits Autoimmune Disease in a Murine Model of Systemic Lupus Erythematosus
}

\author{
Debra B. Gardner, Patricia Rafferty, Peter Bugelski and Bailin Liang \\ Centocor Research and Development
}

USA

\section{Introduction}

Systemic lupus erythematosus (SLE) is an autoimmune disorder characterized by the involvement of multiple organ systems with alternating clinical exacerbations and remissions. Circulating immune complexes and autoantibodies can cause tissue damage and organ dysfunction with manifestations involving the skin, serosal surfaces, central nervous system, and kidneys (Rahman \& Isenberg, 2008).

B cells are believed to play an important role in SLE. B cells can function as APCs, produce cytokines and chemokines contributing to lymphoid regulation, and can respond to stimuli in the microenvironment at local tissues (Ramanujam \& Davidson, 2008). Pathogenic autoantibodies produced by autoreactive B cells are believed to play an important role in the pathogenesis of SLE.

CXCL13 has been shown to be a key mediator of organization of lymphoid tissues. CXCL13 is a B cell chemoattractant that is expressed by peritoneal macrophages and follicular dendritic cells in secondary lymphoid organs, such as the follicles of Peyer's patches, the spleen and lymph nodes. Through interaction with CXCR5, a G-protein coupled receptor, CXCL13 attracts B lymphocytes and promotes migration of small numbers of $T$ helper follicular cells and macrophages (Gunn et al., 1998). CXCL13 is critical for B cell homing and follicle formation in lymph node and spleen, and it is required for the development of lymph nodes and Peyer's patches (Ansel et al., 2000). CXCL13 protein level is elevated in ectopic B cell follicles formed in the inflamed tissues of multiple chronic diseases, and plays an important role in maintaining inflammation by actively recruiting B cells (Carlsen et al., 2004; Magliozzi et al., 2004; Salolonsson et al., 2002; Shi et al., 2001;). CXCL13 has been shown to have increased expression in the thymus and kidney of aged NZB/W F1 mice, and may play a role in breaking immune tolerance in the thymus of autoimmune prone mice (Ishikawa et al., 2001). Treatment with anti-CXCL13 has shown efficacy in animal models of RA and EAE (Bagaeva et al. 2006; Zheng et al., 2005). Because of its function and presence in various pathological conditions, CXCL13 and CXCL13 dependent pathways are thought to be instrumental in the pathogenesis of a variety of diseases where $\mathrm{B}$ cells may play a significant role, including RA, OA, UC, and SLE, and could be potential targets for autoimmune therapy (Table 1 ). 


\begin{tabular}{|c|l|l|}
\hline Human Disease & \multicolumn{1}{|c|}{ Potential role of B cell } & Reference \\
\hline $\begin{array}{c}\text { Systemic Lupus } \\
\text { Erythematosus }\end{array}$ & $\begin{array}{l}\text { Antibody production, T cell activation, Antigen } \\
\text { presentation, cytokine production, lymphoid } \\
\text { neogenesis }\end{array}$ & Lipsky, 2001 \\
\hline Rheumatoid arthritis & $\begin{array}{l}\text { Cytokine production, lymphoid neogenesis, T } \\
\text { cell activation }\end{array}$ & Panayi, 2005 \\
\hline Sjogren's Syndrome & Antibody production, lymphoid neogenesis & Liang, 2007 \\
\hline Autoimmune thyroiditis & Antibody production, lymphoid neogenesis & Yu, 2008 \\
\hline Multiple Sclerosis & Lymphoid neogenesis, T cell activation & Hirotani, 2010 \\
\hline Myasthenia Gravis & Lymphoid neogenesis, antibody production & Meraouna, 2006 \\
\hline
\end{tabular}

Table 1. Role of B cells in human autoimmune diseases.

NZB/W F1 mice develop an autoantibody response against DNA and chromatin antigens, a polyclonal hypergammaglobulinemia and ultimately, severe immune complex mediated glomerulonephritis (Aringer \& Smolen, 2008). These mice have been widely used as a model to study lupus nephritis. TNFa is a pleiotropic cytokine produced by many cell types that plays a key role in the pathogenesis of multiple autoimmune disorders, as well as a controversial role in SLE (Aringer \& Smolen, 2008; Kollias, 1999).

Although individual therapies with anti-TNFa or anti-CXCL13 mAb for additional inflammatory diseases have been explored with limited success, there has not been any attempt to combine the two mabs for the treatment of any disease (Bagaeva et al., 2006; Dick et al., 1996; Ruddle et al., 1990; Zheng et al., 2005). This study was designed to investigate the effect of anti-CXCL13 and anti-TNF $\alpha$ mAbs treatment on disease development in NZB/W F1 mice.

\section{Materials and methods}

\subsection{Antibodies and reagents}

RPMI media, heat-inactivated fetal bovine serum, gentamycin and L-glutamine were purchased from Invitrogen (Carlsbad, CA). Neutralizing rat anti-CXCL13 mAb (MAB4701) was purchased from R\&D Systems (Minneapolis, MN) with an endotoxin level of 1.2 $\mathrm{EU} / \mathrm{mg}$. Anti-TNFa was made at Centocor, and had an endotoxin level of $0.262 \mathrm{EU} / \mathrm{mg}$.

\subsection{Animals and experimental protocol}

$\mathrm{NZB} / \mathrm{W} \mathrm{F}_{1}$ mice aged 10-12 weeks were obtained from Jackson Laboratories (Bar Harbor, $\mathrm{ME}$ ). On day 0 , the study animals were randomly assigned to control or treatment groups ( $\mathrm{n}$ $=15$ /group). An intraperitoneal injection of saline, anti-mCXCL13 mAb (0.5 mg/mouse, 2 times a week, weeks 16-34), anti-TNFa mAb (0.5 mg/mouse, 2 times a week, weeks 16-18, then $0.25 \mathrm{mg} /$ mouse, 2 times a week, weeks 19-34) or a combination of anti-CXCL13 plus anti-TNFa mabs were administered weekly from 16 to 34 weeks of age. Animal were monitored weekly. Urine was collected via free catch (once every 3 weeks starting from 12 weeks of age) and stored at $-80^{\circ}$. Blood was collected every three weeks starting from 16 weeks of age, and serum was stored at $-80^{\circ}$. At the final harvest, spleen, lymph nodes, and kidneys were harvested into appropriate storage buffers before further analysis by in vitro functional assays. This study protocol was reviewed and approved by Centocor's Institutional Animal Care and use Committee. 


\subsection{Flow cytometry analysis of B cell activation status}

Mice were killed at 34 weeks of age and their spleens were removed. A portion of the spleen was placed in cold RPMI-1640 medium supplemented with $10 \%$ fetal bovine serum, 10 $\mathrm{mg} / \mathrm{ml}$ gentamycin, $2 \mathrm{mM}$ L-glutamine, $0.1 \mathrm{mM}$ 2-mercaptoethanol. Red blood cells were lysed in red blood cell lysing buffer (Biowhittaker) on ice for 5 minutes. Splenocytes were stained with optimal concentrations of fluorochrome conjugated mAbs $\left(5 \times 10^{5}\right.$ cells in 200 $\mu l$ of phosphate buffered saline, $1 \%$ bovine serum albumin, $0.1 \%$ sodium azide) in U-shaped microtiter plates at $4^{\circ} \mathrm{C}$ for $30 \mathrm{~min}$, and fixed with $1 \%$ paraformaldehyde. Samples were analyzed on a FACSCalibur Instrument (Becton Dickinson, Mountain View, CA). Antimurine CD23 PE (clone B3B4) and anti-murine CD24 FITC (clone M1/69) were purchased from BD Biosciences (Chicago, IL) and used for analysis of B cell activation.

\subsection{Autoantibody analysis}

Anti-dsDNA autoantibodies were determined by ELISA. Double stranded-DNA coated plates were purchased from DiaSorin (Stillwater, MN). 1:100 diluted serum samples were incubated at room temperature for 2 hours on the plates. Alkaline phosphatase conjugated anti-murine IgG (Southern Biotechnology Associates, Birmingham, AL) was added to the plate for 1 hour followed by incubation with p-nitrophenylphosphate substrate (Sigma, St. Louis, MO) for 30 minutes and the plates were read at OD405 nm. OD values from separate assays were normalized to a single MRL lpr/lpr MRL/MpJ-Faslpr/J positive control serum.

\subsection{Proliferation assays}

B cell proliferation was assessed using $1 \times 10^{6}$ splenocytes stimulated with $2 \mu \mathrm{g} / \mathrm{ml}$ each of anti IgM F(ab') (Pierce Biotechnology) and $5 \mu \mathrm{g} / \mathrm{ml}$ anti-CD40 (BD Pharmingen, Sacramento CA) for 72 hours. Proliferation was assessed using BrDU (Roche Applied Science, Indianapolis, IN) and counting luminescence singles on a TopCount (PerkinElmer, Shelton, CT).

\subsection{Urine total protein/creatinine analysis}

Urine samples were collected from mice via free catch and frozen at $-80^{\circ} \mathrm{C}$ for subsequent analysis of urine total protein/creatinine ratio determined by Ace Analyzer (Alpha Wasserman, West Caldwell, NJ). Urine total protein was measured in undiluted urine and creatinine was measured using urine diluted 1:10 in deionized distilled $\mathrm{H}_{2} \mathrm{O}$.

\subsection{Histologic analysis of kidney pathology}

Kidneys were harvested and immediately immersed in $0.7 \%$ periodate lysine paraformaldehyde (PLP) buffer, composed of $0.1 \mathrm{M}$ phosphate buffer, $0.7 \%$ paraformaldehyde, $75 \mathrm{mM}$ L-lysine and $10 \mathrm{mM} \mathrm{NaIO}$. The kidneys were processed for microscopic examination and embedded in paraffin by routine methods after overnight fixation in PLP buffer. The $5 \mu \mathrm{m}$ thick sections were stained with haematoxylin \& eosin (H\&E) for general morphology. Samples were examined and scored for disease severity in a blinded fashion. Pathology was assessed using the World Health Organization (WHO) classifications (Weening et al., 2004).

\subsection{Immunohistochemical staining}

Spleens were harvested, cut in half along its vertical axis, and one half was suspended in OCT and frozen in 2-methyl-butane cooled with dry ice. Spleen sections were prepared, 
fixed in acetone and incubated in PBS (no azide), then in $0.3 \% \mathrm{H}_{2} \mathrm{O}_{2}$ to quench endogenous peroxidase activity. The sections were blocked using PBS $/ 5 \%$ normal goat serum $/ 0.1 \%$ Tween 20 and stained with biotinylated peanut agglutinin (Vector Labs) and B220 FITC (BD Biosciences). Streptavidin-Horseradish peroxidase (HRP, Southen Biotchnologies) and antiFITC-alkaline phosphatase (AP, Southern Biotechnologies) were used as secondary antibodies. HRP and AP were developed using 3-amino-9-ethyl-carbazole and Fast-Blue BB base (Sigma Chemical Co., St. Louis, MO) respectively. Samples were examined in a blinded fashion.

\subsection{Chemotaxis of purified B cells}

$B$ cells were purified by negative selection using the B cell isolation kit from Miltenyi Biotec (Auburn CA). B cell purity was determined by staining for CD19-positive cells and was $>95 \%$. Purified murine B cells $\left(4 \times 10^{7}\right.$ cells in $10 \mathrm{ml}$ RPMI/10\% FBS) were loaded with calcein dye $(1 \mathrm{mg} / \mathrm{ml}$ in dry DMSO, Molecular Probes, Invitrogen) for one hour at $37^{\circ} \mathrm{C}$. Cells were centrifuged at $1200 \mathrm{rpm}$ for $7 \mathrm{~min}$, then resuspended in PBS/2\%FBS to a final concentration of $1 \times 10^{6}$ cells/ml. CXCL13 (R\&D Systems, Minneapolis, MN) was diluted in PBS/2\%FBS to a final concentration of $750 \mathrm{ng} / \mathrm{ml}$ and aliquoted to a $5 \mu \mathrm{m}$ Neuroprobe (Neuroprobe, Gaithersburg, MD) 96 well chemotaxis apparatus, and $50 \mu \mathrm{l}$ of cells were loaded onto the filter. The chemotaxis plate was incubated for one hour at $37^{\circ}$ $\mathrm{C}$, then washed and centrifuged briefly to bring the cells to the bottom of the well. Fluorescence at the bottom of the well was read on the Tecan (Tecan, Mannedorf, Switzerland).

\subsection{Statistical analysis}

Cell surface marker expression, anti-dsDNA levels, B cell proliferation and chemotaxis were expressed as mean $\pm \mathrm{SE}$ and statistical significance was determined by two tailed analysis of variance by standard $t$ test. For statistical analysis on kidney pathologies, the incidence of severe disease was compared across groups by Fisher Exact test with a Bonferroni adjustment of the nominal type I error to determine the variance among the treatment groups. Rank order histological data was analyzed by ANOVA with Dunn's correction for multiple comparisons. $p$ values $<0.05$ were accepted as significant.

\section{Results}

\subsection{Anti-CXCL13/Anti-TNF $\alpha$ treatment increased follicular B cell and reduced transitional $B$ cells in spleen}

We first examined the phenotype of $B$ cells harvested from the treated mice. Spontaneous autoreactive B cell development occurs in NZB/W F1 mice with decreasing follicular B cells and increasing transitional B cells over time. At 34 weeks, follicular B cells in mice treated with anti-CXCL13/anti-TNFa mAbs were significantly increased as compared to that in mice treated with saline, (Fig. 1), while transitional B cells were significantly decreased (Fig. 2) by treatment with anti-CXCL13/anti-TNF $\alpha$ mAbs. These observations suggested that anti-CXCL13/anti-TNFa mAbs treatment helps to maintain a relatively normal $\mathrm{B}$ cell repertoire in NZB/W F1 mice, potentially interfering with the spontaneous autoreactive B cell development. 


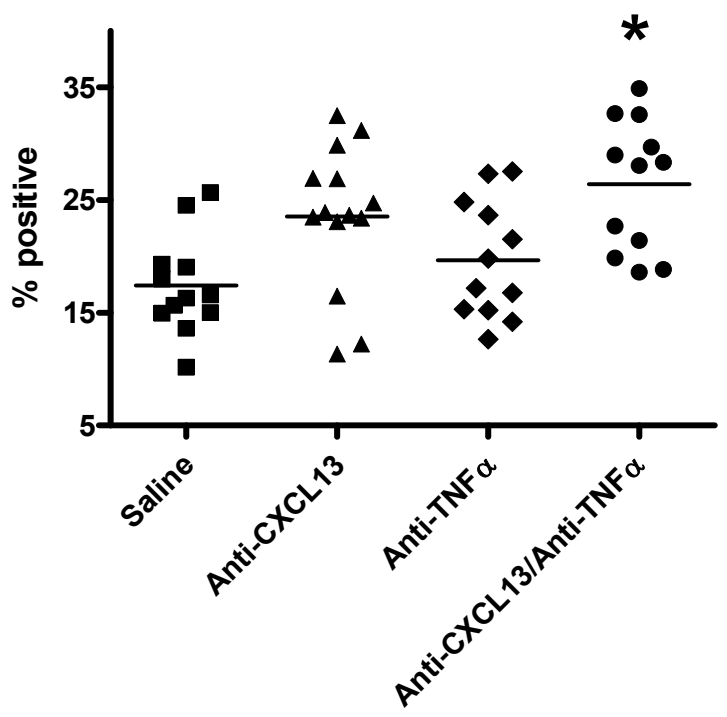

Fig. 1. Anti-CXCL13/anti-TNFa mAbs treatment increased the number of follicular B cells. Total splenocytes were gated on CD19+ B cells and were analyzed with anti-CD23 and antiCD24 antibodies by flow cytometry to determine the population of CD23+CD24- follicular B cells at 34 weeks of age.. * indicates $p<0.05$ vs saline treated control.

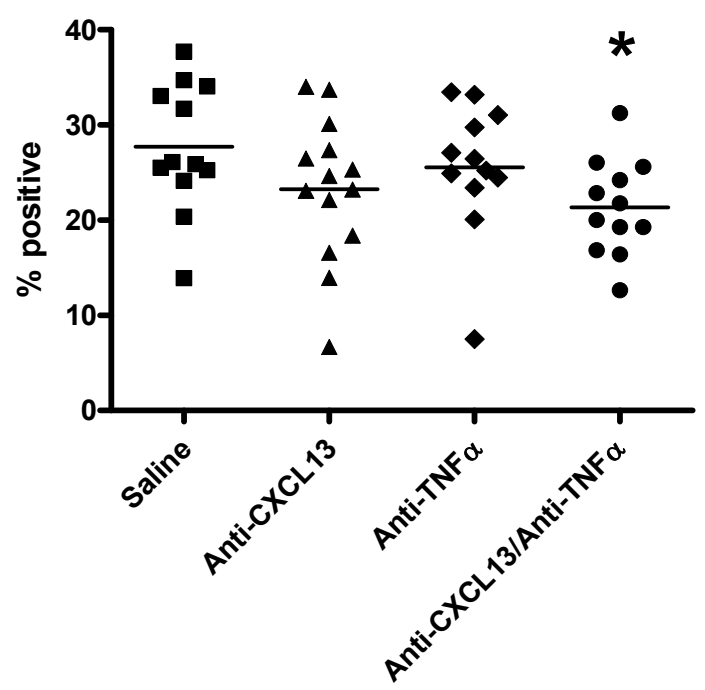

Fig. 2. Anti-CXCL13/anti-TNFa mAbs treatment decreased the number of transitional B cells. Total splenocytes were gated on CD19+ B cells and were analyzed with anti-CD23 and anti-CD24 antibodies by flow cytometry to determine the population of CD23-CD24+ transitional B cells (b) at 34 weeks of age. * indicates $p<0.05$ vs saline treated control. 


\subsection{Anti-CXCL13/Anti-TNFa mAb treatment inhibited anti-dsDNA autoantibody production in the serum}

Since the presence of autoantibodies against dsDNA is a marker of SLE, the effect of antiCXCL13/anti-TNFa mAbs treatment on anti-dsDNA autoantibody production was examined in the serum samples (Fig. 3). Serum anti-dsDNA autoantibody levels increased over the course of the study, and anti-TNFa or anti-CXCL13 mAb treatment alone did not significantly affect the overall anti-dsDNA production as compared to the control treatment with saline. However, anti-dsDNA production in the animals receiving the combination of anti-CXCL13/anti-TNFa mAbs was significantly decreased as compared to the anti-TNFa treatment group (Fig. 3).

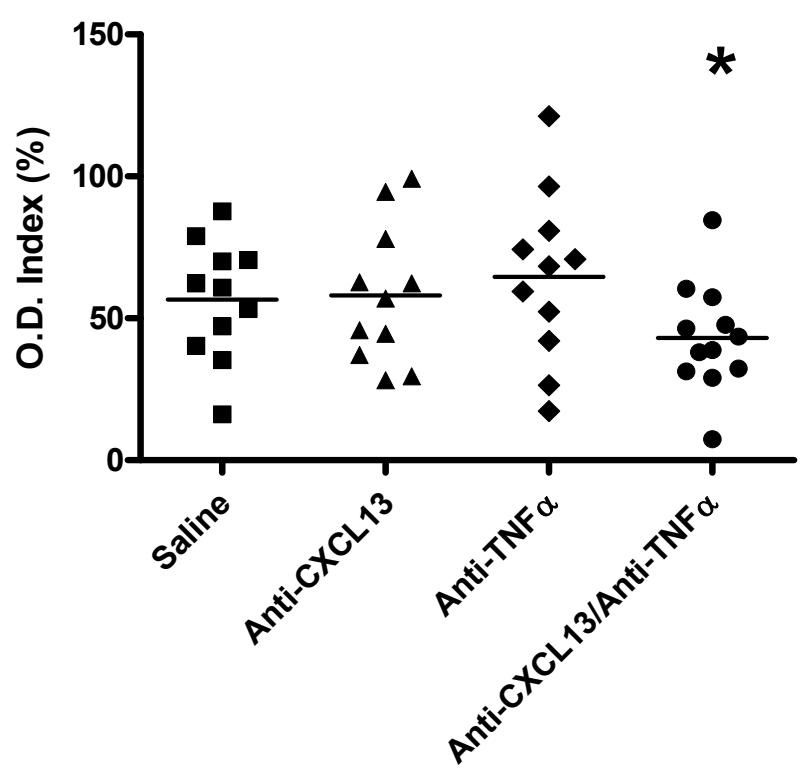

Fig. 3. Anti-CXCL13/anti-TNFa mAbs treatment significantly inhibited serum anti-dsDNA autoantibody as compared to anti-TNFa treatment. Serum samples were analyzed for antidsDNA autoantibody levels by ELISA at 34 weeks of age. O.D. index values represent individual data point normalized throughout the studies to a single positive control serum with anti dsDNA. * indicates $p<0.05$ vs. anti-TNFa mAb treated group.

\subsection{Anti-CXCL13/Anti-TNF $\alpha$ mAb treatment decreased B cell proliferation}

To further investigate whether anti-CXCL13/anti-TNFa mAbs treatment affects the functions of B cells, antibody induced in vitro proliferation was performed to determine Bcell responses using splenocytes isolated from various treatment groups. Ex vivo B-cell proliferation stimulated with anti-CD40/anti-IgM mAbs was significantly depressed by in vivo anti-CXCL13/anti-TNFa mAbs treatment as compared to the saline and single antiTNFa or anti-CXCL13 antibody treatments when mice were 34 weeks old (Fig. 4). These 
data demonstrated that B cells from animals treated with anti-CXCL13/anti-TNFa mAbs were more resistant to ex vivo stimulation and activation.

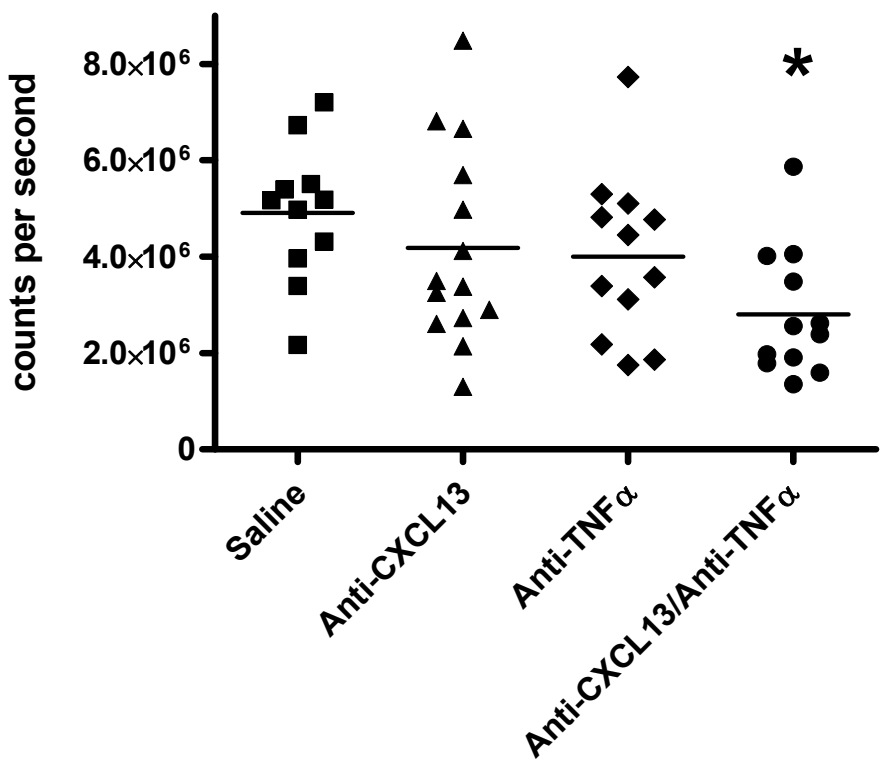

Fig. 4. B cell proliferation is decreased in NZB/W mice treated with anti-CXCL13/antiTNFa mAbs. Cell Proliferation ELISA using BrDU was performed to determine B cell proliferation and results are expressed as counts per second. * indicates $p<0.05$ vs saline control treated groups.

\subsection{Anti-CXCL13/Anti-TNFa mAb treatment suppressed kidney pathology}

Glomerulonephritis is another feature of SLE. To determine the effects of anti-CXCL13/antiTNFa mAbs treatment on kidney function and pathology, we examined urine total protein/creatinine ratios and renal histopathology. Treatment with anti-CXCL13/anti-TNFa mAbs significantly decreased urine total protein/creatinine ratios compared to the antiTNFa, anti-CXCL13, or saline treatment groups (Fig.5).

At 34 weeks of age, periarterial lymphocytic infiltration at the hilus and along the major branches of the renal artery was observed in the PBS control group. There was also evidence of glomerular disease characterized by an increase in mesangial cellularity, collapse of capillary lumina, thickened basement membranes and the presence of amorphous hyaline deposits. These histological changes were associated with an increase in urinary total protein/creatinine ratio (Fig. 5).

Anti-TNFa or anti-CXCL13 mAb treatment alone did not significantly affect the glomerular disease development at week 34 as compared to the control treatment with saline. The beneficial effect of anti-CXCL13/anti-TNFa mAbs treatment on decreasing renal disease severity was reflected by the rank score of disease severity across the groups for glomerular disease (Fig. 6). 


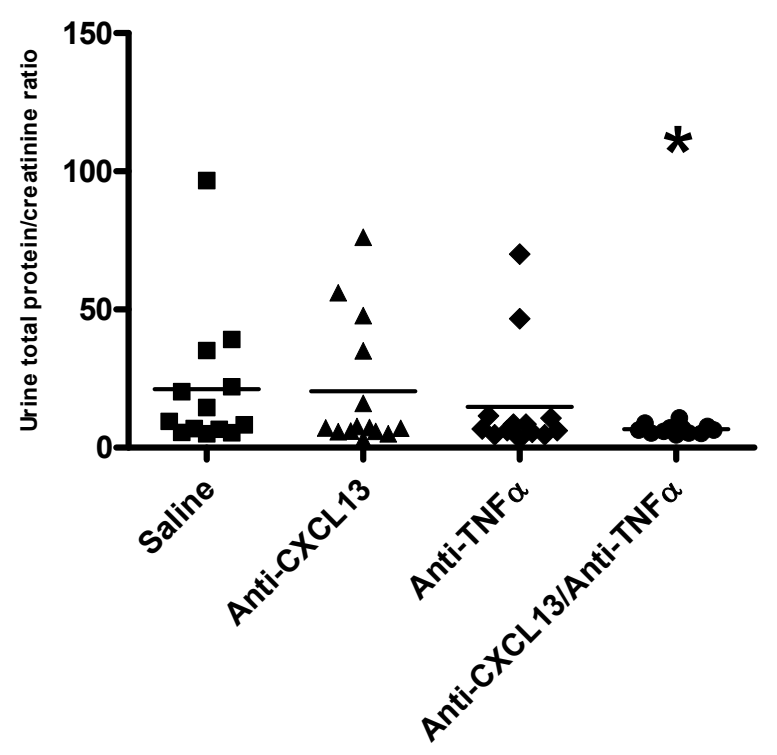

Fig. 5. Anti-CXCL13/anti-TNFa mAbs treatment significantly inhibited urine total protein/creatinine ratios. Urine total protein/creatinine ratios were determined at 34 weeks. * indicates $p<0.05$ vs. saline control treated group.

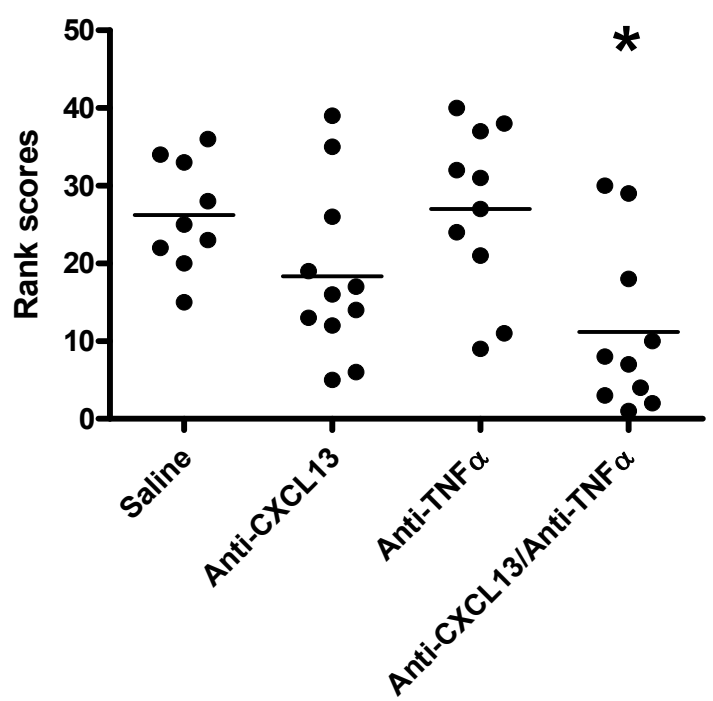

Fig. 6. Anti-CXCL13/anti-TNFa mAbs treatment reduced kidney disease in NZB/W F1 mice. Samples were examined and scored for disease severity in a blinded fashion. Pathology was assessed using the WHO Classifications. * indicates $p<0.05$ vs. saline control treated group. 


\subsection{Anti-CXCL13/Anti-TNFa mAb treatment decreased germinal center formation}

In the splenic germinal center, B cell activation is triggered by ligation with sufficient antigen that has been captured by follicular dendritic cells in a complement and antibodydependent process. B cell activation leads to migration of B cells towards the T cell zone. B cells then receive help from primed T-helper cells also expressing CXCR5 to form follicles and propagate GCs (Fazilleau et al., 2009). In the GCs, immunoglobulin class switching and somatic hypermutation as well as subsequent selection of centrocytes expressing BCR of increased affinity and specificity for the antigen result in the generation of affinity matured, long-lived plasma cells and memory cells.

To investigate the mechanism by which anti-CXCL13/anti-TNFa mAbs treatment has suppressed autoimmune responses in murine SLE, we examined the spleens for germinal center formation. Immunohistochemical staining for germinal center formation reveals that NZB/W mice treated with anti-CXCL13/anti-TNFa mAbs have decreased germinal center formation (Fig. 7). The reduction of the germinal center formation most likely resulted in a decrease of $B$ cell stimulation and activation which subsequently led to suppressed anti-dsDNA autoAb production and glomerular disease development in mice treated with the anti-CXCL13/anti-TNFa mAbs. Mice treated with either mAb alone had germinal center formation similar to that of the saline treated mice in both number and size.

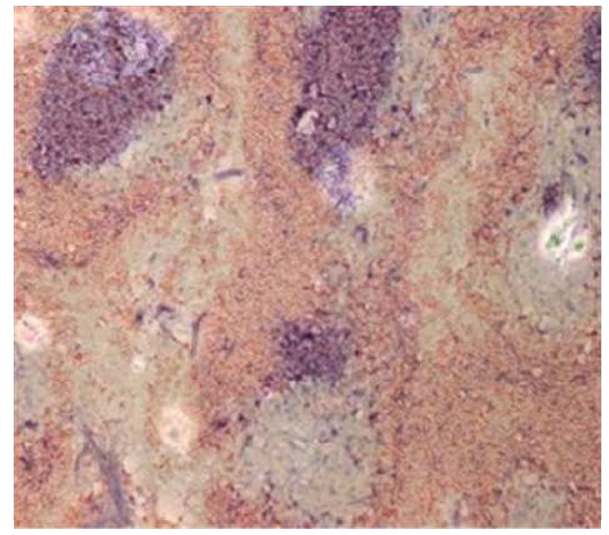

Saline

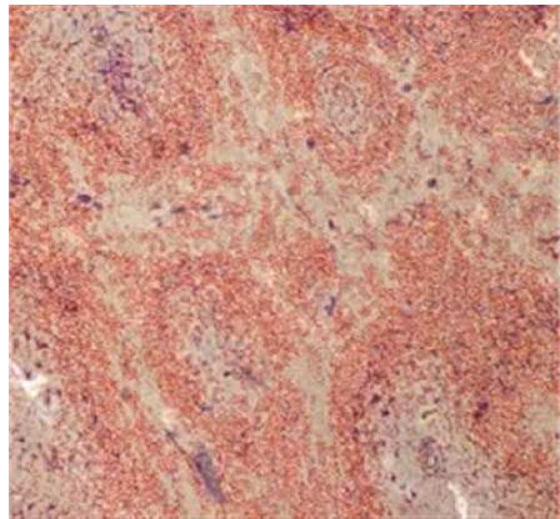

AntiTNF $\alpha /$ antiCXCL13

Fig. 7. Anti-CXCL13/anti-TNFa mAbs treatment decreased germinal center formation in NZB/W mouse spleen. (a) Saline or (b) Anti-CXCL13/anti-TNFa mAb treated spleen sections were stained with peanut agglutinin (blue) and anti-B220 (red) to identify germinal center and B cell zones. (Original magnification 20X).

\subsection{Anti-CXCL13/Anti-TNFa treatment increased chemotactic activity of naive $B$ cells} By treating NZB/W F1 mice with anti-CXCL13/anti-TNFa mAbs, we were able to inhibit autoimmune disease progression in NZB/W F1 mice. CXCL13 has been shown to be a very specific mature B cell chemoattractant. Expression of CXCR5 in mature naïve B cells is high, but after activation and differentiation, B cells lose CXCR5 expression (Hargreaves et al., 
2001). Thus naïve mature B cells would be more responsive to chemotatic migration induced by CXCL13. We investigated the effect of antibody treatment on B cell chemotaxis in our study. After treatment with anti-TNFa alone or the combination treatment of antiCXCL13/anti-TNFa mAbs, the B cells purified from splenocytes were significantly more responsive to in vitro chemotactic stimulation induced by CXCL13 as compared to the B cells from animals treated with saline, or anti-CXCL13 mAb alone (Fig. 8).

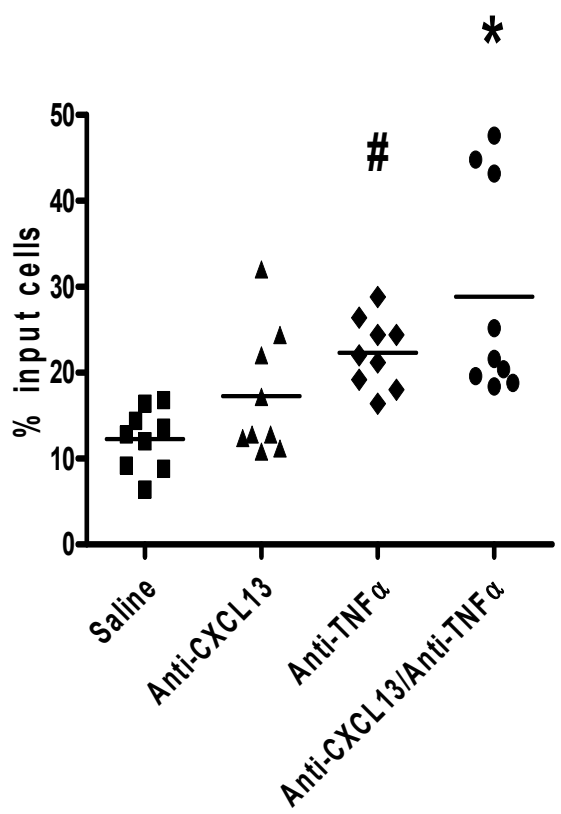

Fig. 8. Anti-CXCL13/anti-TNFa or anti-TNFa mAbs treatment significantly increased chemotaxis of B cells. B cells purified by negative selection over an AutoMacs column were loaded onto a $5 \mu \mathrm{M} 96$ well chemotaxis apparatus and exposed to $750 \mathrm{ng} / \mathrm{ml} \mathrm{CXCL13}$ for one hour. The cells in the bottom well were counted and expressed as a fraction of the cells loaded onto the apparatus. * and \# indicates $p<0.05$ vs saline treated control.

A logical explanation for this observation is that in the saline or anti-CXCL13 mAb treated mice, there are an increased number of activated and differentiated $B$ cells and decreased number of naïve B cells. Activated or differentiated B cells express fewer CXCR5 receptors and thus responded poorly in the chemotaxis assay. In contrast, there are more naïve B cells, which have normal expression of CXCR5 receptors, in the anti-TNFa and antiCXCL13/anti-TNFa mAbs treated mice. This result is highly consistent with the B cell phenotype described earlier.

\section{Discussion and conclusion}

Systemic lupus erythematosus (SLE) is a complex autoimmune disease characterized by hyperactivity of autoreactive $\mathrm{T}$ and $\mathrm{B}$ cell responses against a variety of organs and can have widely varying degrees of severity(Ardoin \& Pisetsky, 2008). Traditional therapies include steroids, mycophenolate, azathioprine, cyclophosphamide and hydroxychloroquine, which 
utilize various mechanisms of action resulting in global immune suppression and significant side effects (Wallace \& Hahn, 2007).

There is a pressing need in the lupus field to find efficacious drugs with more specific immunosuppression. It has been shown by many investigators that various chemokines and cytokines play a role in the progression and pathogenesis of this complex disease (Dorner et al., 2009). It is generally accepted that treatments that would inhibit specific immune cell functions that are responsible for development of SLE may be beneficial for patients. The current study was designed to investigate the effect and mechanism of simultaneous application of two antibodies specific for B cells and inflammation in the inhibition of disease development in a murine model of lupus.

This study shows novel findings that can have applications for potential treatment of autoimmune disease. TNFa is increased in the blood and inflamed kidneys of SLE patients and correlates with disease activity (Ernandez \& Mayadas, 2009; Studnicka-Bencke et al., 1996). TNF expression was also shown to be increased in aged NZB/W mice (Shiffer et al., 2008; Studnicka-Bencke et al., 1996). However, other literature addressing the role of TNFa in SLE suggests that it has a complex function. Administration of TNFa reduces incidence of SLE in young NZB/W F1 mice (Jacob et al., 1991). In NZB/W F1 mice, TNFa deficiency accelerates autoimmune disease and the mice develop severe lupus-like disease including autoantibodies to dsDNA and immune complex glomerulonephritis (Aringer \& Smolen, 2008). TNF $\alpha$ seems to check autoimmunity in some paradigms, and foster inflammation in others, suggesting that other factors not yet identified may contribute to the role played by TNF $\alpha$ in SLE. This actually in part accounts for why we did not observe significant inhibition of autoimmune responses by anti-TNFa treatment alone in the current study.

Anti-dsDNA autoantibody levels in the serum were sometimes associated with disease activity and immune complex formation as well as glomerulonephritis in patients and mice. In our study, treatment with anti-CXCL13/anti-TNFa mAbs resulted in decreased antidsDNA autoantibody levels in the serum of NZB/W F1 mice, as compared with that of the TNFa alone treated mice (Fig 3). This result showed that blocking TNFa alone is not enough to suppress the autoimmune responses in this model as it did in other models. The likely reason could be the heavy involvement of B cells in such responses. The combination therapy with blockade of both TNFa and CXCL13 is superior to just the TNFa blockade alone due probably to the simultaneous suppression of both autoreactive B cells and TNFa. CXCL13 participates in the follicular compartmentalization of B cells in GC and the induction of lymphotoxin ( $\left.\mathrm{LTa}_{1} \beta_{2}\right)$ expression on B cells (Ansel et al., 2000). GCs support the differentiation of memory B cells and long-lived antibody secreting plasma cells. CXCL13 plays an important role in attracting naïve $B$ cells to form germinal centers and can initiate lymphoid neogenesis when expressed aberrantly in mice (Cyster, 1999; Melchers et al., 1999; Takemura et al., 2001). Ectopic CXCL13 was expressed in aged NZB/w mice developing lupus nephritis (Ito et al., 2004). CXCL13 was enhanced in the thymus and kidney of aged NZB/w F1 mice (Ishikawa et al., 2001). There was a decreased number of CXCL13 producing peritoneal macrophages in aged NZB/w mice and the ectopic high expression of CXCL13 results in abnormal B1 cell trafficking during the development of murine lupus (Ito et al., 2004). As expected, treatment of NZB/w mice with a combination of anti-CXCL13 and anti-TNFa $\mathrm{mAbs}$ resulted in decreased germinal center formation in spleen sections in our study (Fig. 7). Combined treatment with anti-CXCL13/anti-TNFa mAbs significantly inhibited ex vivo IgM/CD40 stimulated B cells proliferation (Fig. 4), increased the 
frequency of follicular B cells (Fig. 1), and decreased the frequency of transitional B cells in the spleen (Fig. 2), when the total spleen cell number was not changed (data not shown) in our study. These novel results demonstrate that the combination therapy significantly dampens the autoimmune response in this model by maintaining a relatively normal lymphoid structure as well as B cell repertoire and lowering the activation status of the B cells, resulting in a higher threshold for hypereactivity.

Glomerulonephritis is a consequence of immune complex deposition and subsequent inflammatory cell infiltration and is a pathological hallmark feature of murine SLE. TNFa is highly expressed in glomeruli in all forms of lupus nephritis and the degree of TNFa expression correlates with renal inflammatory activity (Aringer \& Smolen, 2003; HerrerraEsparza et al., 1998). Administration of anti-CXCL13/anti-TNFa mAbs in our study significantly decreased the disease severity of glomerulonephritis in NZB/w F1 mice (Fig. 5 \& 6), as reflected in decreased protein/creatinine ratios and kidney disease scores. In addition to the impact on B cells, neutralization of TNFa and CXCL13 could also result in decreased DC recruitment in the circulation and decreased DC differentiation and maturation into CXCL13 producing DC which has been suggested to play a pivotal role in the development of SLE (Ishikawa, 2002). In addition, treatment of NZB/W F1 mice with anti-TNFa or a combination of anti-CXCL13/anti-TNFa mAbs in our study resulted in a significant increase of mature B cell chemotactic response mediated by CXCL13. In the saline treated group, there were a large number of activated and differentiated $\mathrm{B}$ cells in the spleen, which do not express CXCR5 and therefore cannot respond to CXCL13 mediated chemotaxis. Treatment with anti-TNFa or anti-CXCL13 mAb alone did not result in significant inhibition of autoimmune responses and kidney nephritis in this particular murine lupus model. Treatment with anti-CXCL13 only affects naive mature B cell migration to the germinal center. The activated and memory B cells that contribute significantly to the autoimmune responses and disease development in this animal model were not significantly impacted by the anti-CXCL13 mAb, which limited subsequent efficacy. Furthermore, TNFa can interact and signal through two different receptors: TNFR1 and TNFR2, which can also bind LTa. LTa links with two LT $\beta$ molecules to form a heterotrimer that signals through LT $\beta$ R (Browning et al., 1997). Both of these receptor pathways have been shown to activate expression of many genes, including CXCL13 (Ngo et al., 1999). Treatment with anti-TNFa mAb alone may only block the biologic activity of TNFa in symptoms driven by chronic inflammation, but not necessarily the autoimmune responses mediated by autoreactive B cells and LT $\beta$ R with LTa. LTa would still be able to signal through TNFR or LT $\beta R$ and contribute to increased CXCL13 expression and enhanced chemotaxis which may account for normal GC formation in the spleen of the $\mathrm{TNFa} \mathrm{mAb}$ alone treated mice in our study. Simultaneously blocking both TNFa and CXCL13 allowed interruption of complementary inflammatory pathways, suppressed CXCL13 production and FDC maturation that contributes to the ultimate autoimmune disease development in this murine lupus model.

Further characterization of the effect of neutralization of CXCL13 and TNFa in this disease model might be achieved by use of an anti-CXCL13 antibody with increased potency, to ensure complete neutralization of CXCL13. Also neutralization of LT to evaluate the complete shutdown of the TNFa signaling pathway on the development of disease would be useful to characterize its contribution to disease development. An investigation of the 
effect of the combination of anti-CXCL13 and anti-TNFa in a therapeutic format could determine pathways essential in established disease. Additional studies to further characterize the mechanism of action of anti-CXCL13/anti-TNFa combinatorial treatment could include the contribution of cells from the innate immune system. Specifically, findings have been linked to mast cell stabilization including normalization of the B cell antibody profile for the promotion of innate as well as adaptive immunity during developmental phases of inflammation-induced immune dysfunction (Khatami, 2008, 2011)

In conclusion, this study demonstrated that combined administration of anti-TNFa and antiCXCL13 mAbs significantly inhibited autoimmune responses and autoimmune disease progression in the NZB/W F1 murine model of systemic lupus erythematosus. This combined therapy could provide added benefit for advanced lupus patients that have advanced autoimmune disease.

\section{Acknowledgements}

We are very grateful to Dr. Meera Ramanujam for her scientific discussions and helpful comments.

\section{References}

Ansel, K.M., Ngo, V.N., Hyman, P.L., Luther, S.A., Forster, R., Sedgwick, J.D., Browning, J.L., Lipp, M., \& Cyster, J.G. (2000). A chemokine-driven positive feedback loop organizes lymphoid follicles. Nature, Vol.406, No. No.6793, (July 2000), pp. 309-314, ISSN 0028-0836

Ardoin, S.P., \& Pisetsky, D.S. (2008). Developments in the scientific understanding on lupus. Arthritis Research and Therapy,Vol.10, No.5, (October 2008), pp.218-225, ISSN 14786354

Aringer, M., \& Smolen, J.S. (2003). SLE-Complex cytokine effects in a complex autoimmune disease: tumor necrosis factor in systemic lupus erythematosus. Arthritis Research and Therapy, Vol.5, No.4, (May 2003), pp.172-177, ISSN 1478-6354

Aringer, M., \& Smolen, J.S. (2008). Efficacy and safety of TNF-blocker therapy in systemic lupus erythematosus. Expert Opinion on Drug Safety, Vol.7, No.4, (July 2008), pp.411-419, ISSN 1474-0338

Bagaeva, L.V., Rao, P., Powers, J.M., \& Segal, B. (2006). CXC chemokine ligand 13 plays a role in experimental autoimmune encephalomyelitis. Journal of Immunology, Vol.176, No.12, (June 2006), pp.7676-7685, ISSN 0022-1767

Browning, J.L., Sizing, I.D., Lawton, P., Bourdon, P., Rennert, P., Majeau, g., Ambrose, C., Hession, C., Miatkowski, K., Griffiths, D., Ngam-ek, A., Meier, W., Benjamin, C., \& Hochman, P. (1997). Characterization of Lymphotoxin- $\alpha \beta$ complexes on the surface of murine lymphocytes. Journal of Immunology, Vol.159, No.7, (October 1997), pp.3288-3298, ISSN 0022-1767

Carlsen, H., Baekkevoid, E., Morton, H.C., Haraldsen, G., \& Brandtzaeg, P. (2004). Monocyte-like and mature macrophages produce CXCL13 (B cell-attracting chemokine-1) in inflammatory lesions with lymphoid neogenesis. Blood, Vol.104, No.10, (November 2004), pp. 3021-3027, ISSN 0006-4971

Cyster, J.G. (1999). Chemokines and cell migration in secondary lymphoid organs. Science, Vol.286, No.5447, (December 1999), pp.2098-2102, ISSN 0036-8075 
Dick, A.D., McMenamin, P.G., Korner, H., Scallon, B.J., Ghrayeb, .J, Forrester, J.V., \& Sedgwick JD. (1996). Inhibition of tumor necrosis factor activity minimizes target organ damage in experimental autoimmune uveoretinitis despite quantitatively normal activated $\mathrm{T}$ cell traffic to the retina. European Journal of Immunology, Vol.26, No.5, (May 1996 ), pp.1018-1025, ISSN 0014-2980

Dorner, T., Jacobi, A.M., \& Lipsky, P.E. (2009). B cells in autoimmunity. Arthritis Research and Therapy, Vol. 11, No. 5, (October 2009), pp.247-257, ISSN 0004-3591

Ernandez, T., \& Mayadas, T.N. (2009). Immunoregulatory role of TNFa in inflammatory kidney diseases. Kidney International, Vol.76, No.3, (August 2009), pp.262-276, ISSN 0085-2538

Fazilleau, N., Mark, L., McHeyzer-Williams, L.J., \& McHeyzer-Williams, M.G. (2009). Follicular helper T cells: lineage and location. Immunity Vol.30, No.3, pp.324-335, (March 2009), ISSN 1074-7613

Gunn, M.D., Ngo, V.N., Ansel, M., Ekland, E.H., Cyster, J.G., \& Williams, L.T. (1998). A Bcell-homing chemokine made in lymphoid follicles activated Burkitt's lymphoma receptor-1. Nature, Vol. 391,No.6669, (February 1998), pp.799-803, ISSN 0028-0836

Hargreaves, D.C., Hyman, P.L., Lu, T., Ngo, V., Bidgol, A., Suzuki, G., Zou, Y., Littman, D., \& Cyster, J. (2001). A coordinated change in chemokine responsiveness guides plasma cell movements. Journal of Experimental Medicine,Vol.194, No.1, (July 2001), pp.45-56, ISSN 0022-1007

Herrera-Esparza, R., Barbosa-Cisneros, O., Villalobos-Hurtado, R., \& Avalos-Diaz, E. (1998). Renal expression of IL-6 and TNFa genes in lupus nephritis. Lupus, Vol.7, No.3, (March 1998), pp.154-158, ISSN 0961-2033

Hirotani, M., Niino, M., Sasaki, H. (2010). The role of B cells in Multiple Sclerosis: Implications for B-cell-Targeted Therapy. Current Medicinal Chemistry, Vol. 17, No. 28, (September 2010), pp.3215-3222, ISSN 0929-8673

Ishikawa, S., Sato, T., Abe, M., Nagai, S., Onai, N., Yoneyama, H., Zhang, Y., Suzuki, T., Hashimoto, S., Shirai, T., Lipp, M., \& Matsushima, K. (2001). Aberrant High Expression of B Lymphocyte Chemokine (BLC/CXCL13) by CD11b+CD11c+ Dendritic cells in murine lupus and preferential chemotaxis of B1 cells toward BLC. Journal of Experimental Medicine, Vol.193, No.12, (June 2001), pp.1393-1402, ISSN 0022-1007

Ishikawa, S., Nagai, S., Sato, T., Akadegawa, K., Yoneyama, H., Zhang, Y., Onai, N., \& Matsushima, K. (2002). Increased circulating CD11b+CD11c+ dendritic cells (DC) in aged BWF1 mice which can be matured by TNFa into BLC/CXCL13-producing DC. European Journal of Immunology, Vol.32, No.7, (July 2002), pp.1881-1887, ISSN 0014-2980

Ito, T., Ishikawa, S., Sato, T., Akadegawa, K., Yurino, H., Kitabatake, M., Hontsu, S., Ezaki, T., Kimura, H., \& Matsushima, K. (2004). Defective B1 cell homing to the peritoneal cavity and preferential recruitment of $\mathrm{B} 1$ cells in the target organs in a murine model for systemic lupus erythematosus. Journal of Immunology, Vol.172, No.6, (March 2004), pp.3628-3634, ISSN 0022-1767

Jacob, C.O., Hwang, F., Lewis, G.D., \& Stall, A.M. (1991). Tumour necrosis factor alpha in murine systemic lupus erythematosus disease models: Implications for genetic predisposition and immune regulation. Cytokine, Vol.3, No.6, (November 1991), pp.551-561, ISSN 1043-4666 
Khatami, M. (2008). 'Yin and Yang' in inflammation: duality in innate immune cells function and tumorigenesis. Expert Opinion on Biological Therapy, Vol.8, No.10, (October 2008), pp.1461-1472, ISSN 1471-2598

Khatami, M. (2011). Unresolved inflammation: 'immune tsunami' or erosion of integrity in immune-privileged and immune-responsive tissues and acute and chronic inflammatory diseases or cancer, In: Expert Opinion on Biological Therapy, June 2011, Available from: http://informahealthcare.com/toc/ebt/0/0

Kollias, G., Douni, E., Kassiotis, G., \& Kontoyiannis, D. (1999). The function of tumor necrosis factor and receptors in models on multi-organ inflammation, rheumatoid arthritis, multiple sclerosis and inflammatory bowel disease. Annals of the Rheumatic Diseases, Vol.58, No.Suppl I, (November 1999), pp.I32-I39, ISSN 0003-4967

Liang, B., Eaton-Bassiri, A., Bugelski, P. (2007). B cells and beyond, therapeutic opportunities targeting inflammation. Innflammation and Allergy-Drug Targets, Vol.6, No.3, (September 2007), pp.142-149, ISSN 1871-5281

Lipsky, P. (2001). Systemic lupus erythematosus: an autoimmune disease of B cell hyperactivity. Nature Immunology, Vol.2, No.9, (September 2001), pp.764-766, ISSN 1529-2908

Magliozzi, R., Columba-Cabezas, S., Serafini, B., \& Aloisi, F. (2004). Intracerebral expression of CXCL13 and BAFF is accompanied by formation of lymphoid follicle-like structures in the meninges of mice with relapsing experimental autoimmune encephalomyelitis. Journal of Neuroimmunology,Vol.148, No.1, pp.11-23, ISSN 01655728

Melchers, F., Rolink, A.G., \& Schaniel, C. (1999). The role of chemokines in regulating cell migration during humoral immune responses. Cell, Vol.99, No.4, (November 1999), pp.351-354, ISSN 0092-8674

Meraouna, A., Cizeron-Clairac, G., Le Panse, R., Bismuth, J., Truffault, F., Tallaksen, C., Berrih-Aknin, S. (2006). The chemokine CXCL13 is a key molecule in autoimmune myasthenia gravis. Blood, Vol. 108, No.2, (July 2006), pp.432-440, ISSN 0006-4971

Ngo, V.N., Korner, H., Gunn, M.D., Schmidt, K., Riminton, D., Cooper, M., Browning, J., Sedgwick, J., \& Cyster, J.G. (1999). Lymphotoxin alpha/beta and tumor necrosis factor are required for stromal cell expression of homing chemokines in B and T cell areas of the spleen. Journal of Experimental Medicine, Vol.189, No.2, (January 1999), pp.403-412, ISSN 0022-1007

Panayi, G. (2005). B cells: a fundamental role in the pathogenesis of rheumatoid arthritis? Rheumatology, Vol.44, Suppl.2, (May 2005), pp. 113-ii7, ISSN 0315-162X

Rahman, A., \& Isenberg, D. (2008). Systemic Lupus Erythematosus. New England Journal of Medicine, Vol.358, No.9, (February 2008), pp.929-939, ISSN 0028-4793

Ramanujam, M., \& Davidson, A. (2008)., Targeting of the immune system in systemic lupus erythematosus. Expert Reviews in Molecular Medicine, Vol.10, No.2, (January 2008), pp.1-27,ISSN 1226-3613

Ruddle, N.H., Bergman, C.M., McGrath, K.M., Lingenheld, E.G., Grunnet, M.L., Padula, S.J.,\& Clark, R.B. (1990). An antibody to lymphotoxin and tumor necrosis factor prevents transfer of experimental allergic encephalomyelitis. Journal of Experimental Medicine,Vol.172, No.4, (October 1990), pp.1193-1200, ISSN 0022-1007

Salomonsson, S., Larsson, P., Tengner, P., Mellquist, E., Hjelmstrom, P., \& WahrenHerlenius, M. (2002). Expression of the B cell-attracting chemokine CXCL13 in the 
target organ and autoantibody production in ectopic lymphoid tissue in the chronic inflammatory disease Sjogren's syndrome. Scandanavian Journal of Immunology, Vol.55, No.4, (April 2002), pp.336-342, ISSN 0300-9475

Schiffer, L., Bethunaickan, R., Ramanujam, M., Huang, W., Schiffer, M., Tao, H., Madaio, M., Bottinger, E., \& Davidson, A. (2008). Activated renal macrophages are markers of disease onset and disease remission in lupus nephritis. Journal of Immunology, Vol.180, No.3, (February 2008), pp.1938-1947, ISSN 0022-1767

Shi, K., Hayashida, K., Kaneko, M., Hashimoto, J., Tomita, T., Lipsky, P.E., Yoshikawa, H., \& Ochi, T. (2001). Lymphoid Chemokine B cell-attracting chemokine-1 (CXCL13) is expressed in germinal center of ectopic lymphoid follicles within the synovium of chronic arthritis patients. Journal of Immunology Vol.166, No. 1, (January 2001), pp.650-655, ISSN 0022-1767

Studnicka-Benke, A., Steiner, G., Petera, P., \& Smolen, J.S. (1996). Tumor necrosis factor alpha and its soluble receptors parallel clinical disease and autoimmune activity in systemic lupus erythematosus. British Journal of Rheumatology,Vol.35, No.11, (November 1996), pp.1067-1074, ISSN $0263-7103$

Takemura, S., Braun, A., Crowson C., Kurtin P., Cofield, R., O'Fallon, W., Goronzy, J., \& Weyand, C. (2001). Lymphoid neogenesis in Rheumatoid Synovitis. (2001). Journal of Immunology,Vol.167, No.2, (July 2001), pp.1072-1080, ISSN 0022-1767

Wallace, D.J., \& Hahn B. (2007). DuBois Lupus Erythematosus, 7th edn. Lippincott Williams \& Wilkins, ISBN 978-0-7817-9394-0, Philadelphia,PA

Weening, J.J., D’ Agati, V.D., Schwartz, Seshan, S., Alpers, C., Appel, G., Balow, J., Bruijn, J., Cook, T., Farrario, F., Fogo, A., Ginzler, E., Hebert, L., Hill, G., Hill, P., Jennette, J., Kong, N., Lesavre, P., Lockshin, M., Looi, L., Makino, H., Moura, L., \& Nagata, M. (2004). The classification of glomerulonephritis in systemic lupus erythematosus revisited. Kidney International, Vol.65, No.2, (February 2004), pp.521-530, ISSN 00852538

Yu, S., Dunn, R., Kehry, M., Braley-Mullen, H. (2008). B cell depletion inhibits spontaneous autoimmune thyroiditis in NOD.H-2h4 mice. Journal of Immunology, Vol.180, No.11, (June 2008), pp.7706-7713, ISSN0022-1767

Zheng, B., Ozen, Z., Zhang, X., De Silva, S., Marinova, E., Guo, L., Wansley, D., Huston, D., West, M., \& Han, S. (2005). CXCL13 neutralization reduces the severity of collageninduced arthritis. Arthritis and Rheumatism, Vol.52, No.2, (February 2005), pp.620626, ISSN 0004-3591 


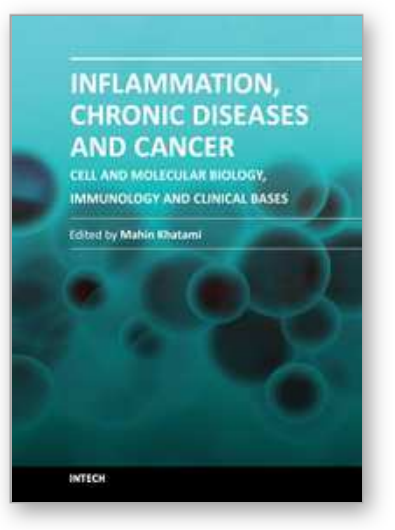

\author{
Inflammation, Chronic Diseases and Cancer - Cell and Molecular \\ Biology, Immunology and Clinical Bases \\ Edited by Dr Mahin Khatami
}

ISBN 978-953-51-0102-4

Hard cover, 430 pages

Publisher InTech

Published online 09, March, 2012

Published in print edition March, 2012

This book is a collection of excellent reviews and perspectives contributed by experts in the multidisciplinary field of basic science, clinical studies and treatment options for a wide range of acute and chronic inflammatory diseases or cancer. The goal has been to demonstrate that persistent or chronic (unresolved or subclinical) inflammation is a common denominator in the genesis, progression and manifestation of many illnesses and/or cancers, particularly during the aging process. Understanding the fundamental basis of shared and interrelated immunological features of unresolved inflammation in initiation and progression of chronic diseases or cancer are expected to hold real promises when the designs of cost-effective strategies are considered for diagnosis, prevention or treatment of a number of age-associated illnesses such as autoimmune and neurodegenerative diseases as well as many cancers.

\title{
How to reference
}

In order to correctly reference this scholarly work, feel free to copy and paste the following:

Debra B. Gardner, Patricia Rafferty, Peter Bugelski and Bailin Liang (2012). Anti-CXCL13 and Anti-TNF $\alpha$ Monoclonal Antibodies Combinatorial Treatment Inhibits Autoimmune Disease in a Murine Model of Systemic Lupus Erythematosus, Inflammation, Chronic Diseases and Cancer - Cell and Molecular Biology, Immunology and Clinical Bases, Dr Mahin Khatami (Ed.), ISBN: 978-953-51-0102-4, InTech, Available from:

http://www.intechopen.com/books/inflammation-chronic-diseases-and-cancer-cell-and-molecular-biologyimmunology-and-clinical-bases/anti-cxcl13-and-anti-tnf-monoclonal-antibodies-combinatorial-treatmentinhibits-autoimmune-disease-i

\section{INTECH}

open science | open minds

\section{InTech Europe}

University Campus STeP Ri

Slavka Krautzeka 83/A

51000 Rijeka, Croatia

Phone: +385 (51) 770447

Fax: +385 (51) 686166

www.intechopen.com

\section{InTech China}

Unit 405, Office Block, Hotel Equatorial Shanghai

No.65, Yan An Road (West), Shanghai, 200040, China 中国上海市延安西路65号上海国际贵都大饭店办公楼 405 单元

Phone: +86-21-62489820

Fax: $+86-21-62489821$ 
(C) 2012 The Author(s). Licensee IntechOpen. This is an open access article distributed under the terms of the Creative Commons Attribution 3.0 License, which permits unrestricted use, distribution, and reproduction in any medium, provided the original work is properly cited. 